\section{Emissions: Canada should not be isolating itself}

It should be possible to draw up a fair, ambitious and legally binding treaty on climate change after this week's United Nations summit in Copenhagen (see go.nature.com/ sRCuKV). But the next few years are going to be crucial if we are to stand a reasonable chance of keeping global warming to below an average of $2{ }^{\circ} \mathrm{C}$

Pessimistic media reports reflect the views of only a few world leaders, including Canada's, who lack ambition and imagination. Other leaders, including the US and Chinese presidents and the summit host, Prime Minister Lars Løkke Rasmussen of Denmark, are still pushing for a strong agreement.

The science is clear. To limit average global warming to the $2{ }^{\circ} \mathrm{C}$ agreed by world leaders at July's G20 meeting, total greenhouse-gas emissions will have to peak around 2015 and then decline sharply. If emissions are more than $25 \%$ above 2000 levels in 2020, the risk of exceeding $2{ }^{\circ} \mathrm{C}$ in this century would be more than $50 \%$, even if emissions were reduced to low levels by 2050 (M. Meinshausen et al. Nature 458, 1158-1162; 2009).

Canada should be playing a strong multilateralist part, fulfilling its international commitments, offering constructive proposals on difficult and tense issues, and looking for compromise when positions are entrenched. But Canada has not been constructive and it has isolated itself. It is the only country to have signed up for a target under the Kyoto Protocol and then stated that it has no intention of meeting it. Canada has put forward positions that have heightened, rather than eased, tension. It has argued that developing countries should take on 'hard caps' (which emissions must not exceed, even if production increases) - something no other country advocates. And it is uncompromising on issues such as using 1990 as a base year, which has blocked agreement.

The Copenhagen summit is a big challenge because industrialized countries such as Canada have yet to accept fully that they have a greater responsibility than developing countries for the problem of climate change, and a greater capacity to solve it. Because rich countries have used up so much atmospheric space in the course of their own development, they need to deliver substantial support so that poorer countries can develop without following our dirty path. Wealthy countries need to provide clean technologies and financing some US $\$ 160$ billion per year - so that developing countries can curb their own emissions and adapt to climate changes that are already happening.

Unfortunately, Canada is among the rich countries that have impeded progress in negotiations, and not just because it has disavowed its commitments under the Kyoto Protocol. Its 2020 emissions-reduction target is the weakest of all Kyoto parties' and it has not supported any options to deliver financing to the developing world. The needs are great. But so are the responsibilities and the opportunities. Canada and other wealthy nations can and must do more.

David Suzuki David Suzuki Foundation, Suite 219, 2211 West 4th Avenue, Vancouver, British Columbia,

Canada V6K 4S2

e-mail: contact@davidsuzuki.org

\section{Emissions: taking a collaborative lead will work better}

The developing world is urging rich countries to take the lead in tackling climate change, as Jiahua Pan points out in his Opinion article (Nature 461, 1055; 2009). However, in doing so, they should not overlook opportunities for technological collaboration as a means to work towards achieving a global low-carbon economy.

Within the past few weeks, both the United States and China have announced targets to curb their carbon emissions. With the climate-change summit in Copenhagen this week, the world is expecting further dialogue and collaboration on climate change between the two biggest carbon emitters. Developed nations will benefit, in the long run, from technological cooperation with developing countries.

Many carbon-emission reduction technologies, such as carbon capture and storage, are still at an experimental stage, with the United States, Germany and Japan leading their research and development. These countries should expand the scope of their experiments to test commercial feasibility. Many new power plants will be constructed in developing nations, offering a good opportunity for cooperative projects with developed countries to apply new technologies, if agreements can be reached on clean-energy and emissionsreduction programmes.

Such fruitful collaborations on technical projects will increase the chances of successful implementation of practical approaches in addressing climate change.

Xufeng Zhu Zhou Enlai School of Government, Nankai University, 94 Weijin Road, Tianjin, 300071, China e-mail: zhuxufeng@nankai.edu.cn

For more about the Copenhagen conference, see page 714 and go.nature.com/sRCUKV.

\section{Need for religions to promote values of conservation}

Boris Hillmann and Jan Barkmann suggest in their Correspondence that the world's religions could make a positive contribution to biodiversity conservation (Nature 461, 37; 2009). This was also a major theme in the interfaith Parliament of the World's Religions, which as held in Melbourne, Australia, this month (www.parliamentofreligions.org).

But the attitudes of different religions towards conservation can vary greatly. Compare, for example, the anthropocentric mainstream Muslim position that humanity has responsibility for Allah's creation, which has been given to us as a gift, with the biocentric Jain belief that every being - animal, plant or human has a soul and should be treated with respect.

Religious practitioners are more likely to help fund the protection of species and habitats if their religion formally values biodiversity. Until recently, most faiths had not formulated a stance on conservation practice, as few religious traditions explicitly promote it. Networks such as the Forum for Religion and Ecology at Yale University (http:// fore.research.yale.edu) have promoted discourse by searching for environmental inspiration in religious teachings.

It is not enough to rely on the idea that sacred places may act as de facto biodiversity reserves, because sacred sites can still be overexploited. Embedding some of the values of conservation biology into the teachings and practice of the four billion people affiliated with one of the world's 11 mainstream faiths is a promising way forward.

Matthew Hall Centre for Middle Eastern Plants, Royal Botanic Garden Edinburgh, Edinburgh EH3 5LR, UK email:m.hall@rbge.ac.uk John Grim, Mary Evelyn Tucker Yale University School of Forestry and Environmental Studies, New Haven, Connecticut 06511, USA

Contributions may be submitted tocorrespondence@nature. com. Published contributions are edited. Please see the Guide to Authors at go.nature.com/ cMCHno. Comments and debate are also welcome at our blog Nautilus: http://blogs.nature. com/nautilus. 